As might be expected, costs for the literary faculties are considerably lower. When calculated on the same basis of one research worker being equivalent to ten undergraduates, the average figure is $£ 416$ a year as compared with $£ 740$ a year in the scientific faculties. Assistants' wages, supplies and services are expensive items in the scientific budgets.

\section{DEPOPULATION AND RURAL LIFE IN SCOTLAND}

TN 1948, the Social Survey of the Central Office of Information was asked by the Department of Health for Scotland to carry out, in selected areas of Scotland, an investigation into rural living conditions and the causes of rural depopulation. The three areas were the Solway counties of south-west Scotland, the Tweed Basin, and north-east Scotland, within the counties of Aberdeen and Banff.

The Solway area was the subject of a detailed report. In the other two areas the results of the investigations showed that conditions there differed only slightly from those obtaining in the south-west. A cursory examination of the three sets of results revealed that, in the districts that were surveyed, the main problems of rural life remained the same, although sometimes presented with slightly different emphases. It seems possible, therefore, that the same kind of remedial measures would be applicable to all the survey areas. On the other hand, the analyses of the results from the Solway survey left in doubt the fundamental factors that had caused the decline of the population of the area. An attempt has therefore been made to isolate these factors with the aid of material from the Tweed and the Aberdeen inquiries, together with the results of a postal questionnaire sent to persons known to have migrated in the preceding twenty years*.

A summary of the major findings showed that, in the rural areas studied, a tenth of the adult population said they would prefer to move away; but the proportion varied from county to county. Wigtownshire and Peebleshire showed a ratber higher proportion of potential migrants (those counties being more isolated and less well served with modern amenities than others), while in the better-served counties of Selkirk and Berwick the proportion was somewhat lower than the average. Only a small minority (17 per cent) of the potential migrants had actually made plans to move within a year of the date of interview, giving an average of $\mathbf{1} \cdot \mathbf{7}$ per cent of the adult population of the survey areas whose desire to move had reached the stage of action. People related to earlier migrants tended to become potential migrants themselves slightly more often than people who were not so related. They were also rather more conscious of the advantage of urban forms of life.

Analysis showed that national and local government, the building industry and the personal service industries produced a rather higher than average proportion of potential migrants. In contrast, there was a significantly smaller proportion of potential

* Depopulation and Rural Life in the Solway Counties. By Bertram Hutchinson. (N.S. 120.) Pp. iv $+110+25$ plates. Depopulation and Rural Life in the Tweed Valley. By Bertram Hutchinson. (N.S. 120b.) Pp. fi +60 . Depopulation and Rural Life in Aberdeen, By Bertram Hutchinson. (N.S. 120c.) Pp. 63. Depopulation and Rural 1949.) migrants from among those employed in agriculture, and from people who were retired or had no occupation. On the other hand, the desire to migrate was most frequently found among professional workers, clerical workers and the managerial and executive grades. The supervisory and skilled operative grades produced a smaller than average proportion of potential migrants. Within agriculture, farmers, bailiffs and foremen showed the smallest proportion of potential migrants of all occupations.

The desire to move was expressed rather more often by the young and the single people then by the old and the married. Thus, while of the general population of the survey areas 20 per cent were under thirty years of age, among the potentially migrant group 37 per cent were of this age.

The situation of the informant's dwelling had only a small degree of association with his desire to move or to remain. Thus, people living in an isolated house, or in a house situated in a small lonely group, were less likely to wish to move away than people living in the burghs. Similarly, people whose houses had no road access were less likely to wish to move than people living on main and other metalled roads. There was a greater degree of association, however, between the informant's subjective estimate of the convenience of the location of his home and the desire to move. Nearly three times as many people who said their homes were situated inconveniently as of those who thought them conveniently located said they wished to move to a town. The majority of houses thought 'inconveniently' placed, however, were in burghs or villages. An analysis of some of the actual conditions of housing and amenity in the survey areas showed that the households of potential migrants were, slightly more often than the average, enjoying a main water supply and main drainage, and were more often provided with gas, electricity, telephone and refuse collection services.

Visits to burghs were rather more frequent among potential migrants than among other people. The reasons for their visits laid a rather greater emphasis upon social calls and entertainments than upon business and marketing, compared with the rest of the rural population.

The reasons which potential migrants gave for their preference appeared to fall into the following major categories: the desire for a better job ; the desire to escape rural loneliness and stagnation; the wish for change and new experience; and miscellaneous answers of which a considerable proportion referred to factors such as marriage, transfer by employer, and personal family reasons. Replies to a postal questionnaire showed that migrants had made a considerable advance in occupational skill and position after leaving rural areas. As many as 50 per cent of past migrants said they would not have moved away from the countryside had a better choice of jobs been available there.

From these findings it is difficult to point without hesitation to any single factor which has led to the process of depopulation. The explanations given by past and potential migrants for their wish to migrate offer the most solid indications as to the causes of rural depopulation. Both in the past and to-day the desire for occupational advance appears to have been the most frequent cause of migration, while evidence suggests that migration has, in fact, been accompanied by a rise in occupational status. Secondly, there was a desire to escape from the stagnation and solitude of rural life, a desire for new experience and the more 
vivid social life of the towns. Thirdly, there was the migration brought about by rural-urban intermarriage (probably accelerated by the War) resulting in homes being set up in the towns where the husband or wife was already living. Fourthly, some moved or wished to move for a number of circumstantial reasons, such as ill-health, family reasons, transfer by employer, and so on. Finally, there was a miscellaneous group of reasons such as bad climate in the rural areas, or children's education.

These answers make little reference to the general environmental conditions of rural life, such as housing, public services, entertainments, and transport. A careful analysis of the environmental conditions of informants showed that in many respects potential migrants were no worse off than the remainder of the population, and in some ways were actually better equipped on an average. There is, in fact, a suspicion that small improvements in housing and amenities in rural areas have served to whet the appetite of those who have profited by them rather than to satisfy it. It cannot be said that material factors at any time take the centre of the stage in the examination of the causes of depopulation.

The aim, therefore, must be to make possible a satisfactory mode of life for the rural people on a standard which can be compared favourably with urban conditions. In this way any sense of inferiority among rural dwellers can be avoided, while fulfilling their need for self-respect. Such an outcome can be achieved in part by the provision of a more varied field of rural employment ; but it must probably be accompanied by fundamental improvements in rural amenities. Better jobs in the country, it seems, must have their counterpart in the possibility of a standard of living that the people have come to expect.

\section{ABSORPTION OF POLYMYXIN BY BACTERIA}

\section{By DR. A. V. FEW and DR. J. H. SCHULMAN \\ Department of Colloid Science, Free School Lane, Cambridge}

$\mathrm{T}$

HE five members of the polymyxin group of antibiotics, $A, B, C, D$ and $E$, have been shown to possess similar antibacterial spectra and potency ${ }^{3}$. Considerable evidence has accumulated ${ }^{2-4}$ indicating that the polymyzins are rapidly bactericidal and not bacteriostatic, although in one paper ${ }^{5}$ it was suggested that polymyxins $A$ and $B$ are bactericidal for small inocula and bacteriostatic for large inocula. In assay experiments, the marked dependence of the minimum lethal concentration of polymyxin upon the size of the inoculum ${ }^{3,4,6,7}$ suggests that bacterial absorption of the antibiotic is high.

This communication describes experiments on the absorption of polymyxin $E$ by washed suspensions of several Gram-negative and -positive bacteria. The releass of soluble cell constituents, initiated by the presence of the antibiotic, and possessing an absorption maximum in their ultra-violet spectra at $260 \mathrm{mu}$, has been followed concurrently. Free purines and pyrimidines contribute to this maximum ${ }^{8,9}$. Since microbiological assay of polymyxin is both tedious and not capable of high precision, a simple and accurate method has been developed based upon the

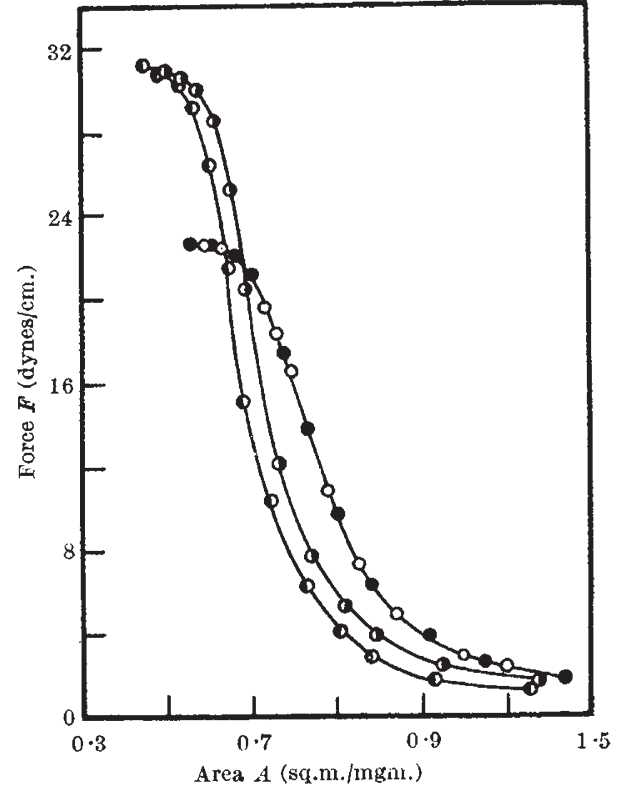

Wig. 1. Force/area curves for polymyxins $A, O-O-; B$; (w.w.) ammonium sulphate solution, $p \mathrm{H} 4.5$, at $20^{\circ} \mathrm{C}$.

observation ${ }^{10}$ that the polymyxins form stable unimolecular films at the air/water interface when spread upon 70 per cent $(w / w)$ ammonium sulphate solution. Fig. 1 shows the force/area curves for polymyxin $A$, $B, D$ and $E$ obtained using a standard LangmuirAdam surface balance. Full details of the properties of these films and estimations of the molecular weights of the antibiotics have been described elsewhere ${ }^{10}$. To determine the concentration of polymyxin in aqueous or buffered solution, an aliquot is sproad upon the ammonium sulphate solution, and the area at a surface pressure of $\mathbf{1 6}$ dynes $/ \mathrm{cm}$. (where compressibility is at a minimum) is compared with that of the standard force/area curve of the particular polymyxin at the same surface pressure. The concentration of the polymyxin solution then follows by proportion. The method is rapid, requires less than $0.5 \mathrm{ml}$. of solution, and can detect the polymyxins at a concentration of less than $5 \mu \mathrm{gm} . / \mathrm{ml}$. to \pm 10 per cent and at $100 \mu \mathrm{gm} . / \mathrm{ml}$. to \pm 1 per cent.

For the absorption experiments the bacteria were harvested after $16 \mathrm{hr}$. growth at $37^{\circ} \mathrm{C}$. and washed four times with $0.01 M$ phosphate buffer, $p \mathrm{H} 6 \cdot 3$,

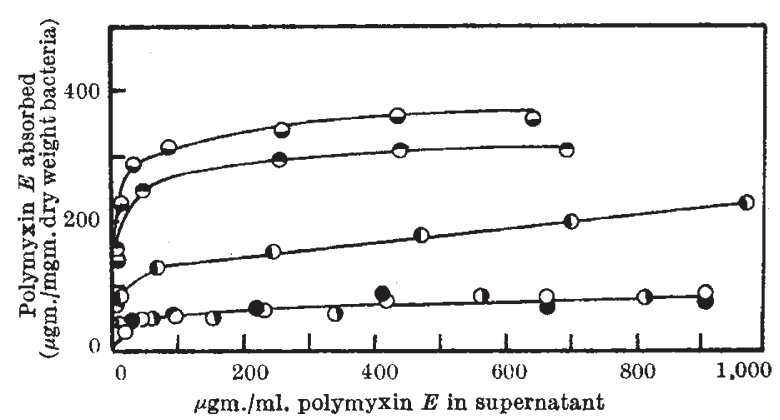

Fig. 2. Bacterial absorption of polymyxin $E$. P8. denitrificans,

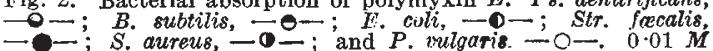
phosphate buffer, $p$ H $6 \cdot 3,25^{\circ} \mathrm{C}$. 